\title{
Experiments Design for Hardness Optimization of the Ni-Cr Alloy Electrodeposited by Pulse Plating
}

\author{
I. Imanieh ${ }^{\dagger}$, E. Yousefi, A. Dolati and M.R. Mohammadi \\ Department of Materials Science and Engineering, Sharif University of Technology, Azadi Ave., Tehran, Iran \\ [Manuscript received 4 March 2013, in revised form 14 May 2013] \\ (c) The Chinese Society for Metals and Springer-Verlag Berlin Heidelberg
}

\begin{abstract}
The hardness of the $\mathrm{Ni}-\mathrm{Cr}$ alloy which is electrodeposited in chloride solution, is optimized by design of experiment method (central composite design). Various parameters were evaluated in order to find significant factors in this process. Frequency, duty cycle, current density and temperature were selected as effective factors. Analyses of variance (ANOVA) were performed on the results of the designed experiments. The best model which can predict the hardness of the $\mathrm{Ni}-\mathrm{Cr}$ alloy electrodeposits was found whereas the frequency and quadratic behaviour of the current density were the most significant model terms. Serious interaction of the current density with frequency and duty cycle also were found in this model. Finally the optimum conditions of the factors for obtaining the maximum hardness of the $\mathrm{Ni}-\mathrm{Cr}$ alloy were found. $\mathrm{Ni}-\mathrm{Cr}$ alloy with hardness $828 \mathrm{HV}$ (electrodeposited with frequency $63 \mathrm{~Hz}$, current density $1800 \mathrm{~A} / \mathrm{m}^{2}$, duty cycle $75 \%$ and temperature $31{ }^{\circ} \mathrm{C}$ bath) were assessed as the optimum deposit. The deposit under the optimum condition was investigated by scanning electron microscopy (SEM), EDX analysis, polarization method and microhardness.
\end{abstract}

\section{KEY WORDS: Ni-Cr; Electrodeposition; Hardness; Optimization}

\section{Introduction}

Excellent nickel resistance to general corrosion results in large applications of it as a base metal in industry. Electrochemical corrosion of nanocrystalline (nc) Ni and conventional coarse-grained Ni were studied by several researchers ${ }^{[1-3]}$. In order to reduce pitting corrosion of the nickel, chromium alloying can be effectively beneficial ${ }^{[4]}$. The $80 \mathrm{Ni}-20 \mathrm{Cr}$ alloy (wt.\%) is a material having different applications in different fields such as strain gauge applications or electronic industry (production of resistor elements). Particularly it is a protective material in high temperature oxidizing environment because it becomes passive in these environments ${ }^{[5,6]}$.

In pulse electrodeposition, it is possible to control the grain size and coating composition by adjusting the mean current density, frequency and duty cycle ${ }^{[7]}$. It is possible to increase the hardness of the $\mathrm{Cr}$ or

† Corresponding author. Ph.D. Candidate; Tel.: $\quad+98$ 9122817419; E-mail address: iman.imanieh@gmail.com (I. Imanieh)

DOI: $10.1007 / \mathrm{s} 40195-013-0120-1$
Ni-Cr alloy deposits by using pulse plating ${ }^{[8]}$. High hardness of the Ni-Cr alloy electrodeposits has attracted great attention of researchers to improve their mechanical properties by various methods ${ }^{[9-11]}$. Design of experiment (DOE) is one of the most popular methods in optimization process. Researchers are using this method for different purposes ${ }^{[12-17]}$. Conventional methods of optimization need several experiments to find the effect of significant factors on the response without finding the interaction of factors. Recently, many practical experimental design methods are investigated and used in optimization process. Response surface methodology (RSM) was used by many researchers to analyze some effective factors in various systems $^{[18-22]}$. In the present study, the RSM based on central composite design (CCD) is employed to recognize the optimum conditions of the hardness in the Ni-Cr alloy pulse electrodeposition. The CCD can be run sequentially and it has the ability of finding the linear or curvature effect of the variables on the responses. Also it can recognize the interaction of two factors on each other. On the other hand, the CCD is very efficient because it provides much information about the experiments effect and overall 
experimental errors in a minimum number of required runs. Design of the experiment in CCD is very flexible and this method does not have many limitations. Therefore CCD can be used in many applications and purposes $^{[23]}$.

\section{Experimental}

Steel and stainless steel plates were used as cathode $(5 \mathrm{~mm} \times 20 \mathrm{~mm})$ and anode $(10 \mathrm{~mm} \times 20 \mathrm{~mm})$, respectively. The Ni-Cr alloy deposits were electrodeposited in a plating bath containing $100 \mathrm{~g} / \mathrm{L}$ $\mathrm{CrCl}_{2} \cdot 6 \mathrm{H}_{2} \mathrm{O}$ and $30-40 \mathrm{~g} / \mathrm{L} \mathrm{NiCl}_{2} \cdot 6 \mathrm{H}_{2} \mathrm{O}$ as metal salts, 35-40 g/L formic acid 95\%, 30-40 g/L boric acid, $80 \mathrm{~g} / \mathrm{L}$ sodium citrate dehydrate as the complex agent and 15-50 g/L conductive materials ( $\mathrm{NaBr}$ and $\mathrm{NH}_{4} \mathrm{Cl}$ ). The bath temperature range was between 30-70 ${ }^{\circ} \mathrm{C}$ (as shown in Table 1). Before electrodeposition, the surface of the cathode was mechanically polished and then it was ultrasonically cleaned in acetone and dried with a hot air blaster.

Table 1 Bath composition for electrodeposition of the Ni-Cr alloy deposits

\begin{tabular}{cc}
\hline Constituent & Amount \\
\hline $\mathrm{NiCl}_{2} \cdot 6 \mathrm{H}_{2} \mathrm{O}$ & $(30-40) \mathrm{g} / \mathrm{L}$ \\
$\mathrm{CrCl}_{2} \cdot 6 \mathrm{H}_{2} \mathrm{O}$ & $100 \mathrm{~g} / \mathrm{L}$ \\
Formic acid $95 \%$ & $(35-40) \mathrm{g} / \mathrm{L}$ \\
$\mathrm{NaBr}$ & $15 \mathrm{~g} / \mathrm{L}$ \\
$\mathrm{NH}_{4} \mathrm{Cl}$ & $50 \mathrm{~g} / \mathrm{L}$ \\
Boric acid & $(30-40) \mathrm{g} / \mathrm{L}$ \\
Sodium citrate dehydrate & $80 \mathrm{~g} / \mathrm{L}$ \\
pH & 4.6 \\
Temperature & $(30-70){ }^{\circ} \mathrm{C}$ \\
\hline
\end{tabular}

Design of experiments was performed by Design Expert 7 software. The hardness of the Ni-Cr alloy electrodeposits was optimized by CCD (Central Composite Design) method. This study is focused on significant factors like frequency, duty cycle, current density and temperature. The significance of these factors and their operating ranges was found based on the preliminary experiments (not shown in the manuscript). The interaction and main effect of these substantial factors were evaluated by electrodeposition of the Ni-Cr alloys in various conditions. Electrolyte $\mathrm{pH}$ also is substantial parameter in $\mathrm{Ni}-\mathrm{Cr}$ alloy electrodeposition but serious effect of the $\mathrm{pH}$ on quality of the deposits, made it as an unchangeable factor during electrodeposition. On the other hand, when the $\mathrm{pH}$ adjusts in less or more than a special value, the ions will not deposit on the cathode surface or a very weak adhesion will be obtained. So $\mathrm{pH}$ was adjusted on the best value (4.6) and did not consider in DOE process. 30 experiments were designed by CCD with various conditions of four considered factors. The center point was repeated for five times for finding the amount of noises and errors on the system. Optimum condition was obtained by finding an appropriate prediction model and analyzing the surface and contour plots. Final results of the optimum condition were considered for checking the reliability of the selected model. SEM, EDX and micro hardness method were used in consideration process and corrosion behavior of the optimum sample was also studied in $3.5 \mathrm{wt} . \%$ $\mathrm{NaCl}$ solution.

\section{Results and Discussion}

Table 2 illustrates the conditions of 30 experiments which performed in this study. 5 replications in the center point also were carried out for evaluating the presence of noises in the system.

Analyzing the final results of designed experiments was conducted by ANOVA. Eq. (1) relates the hardness $(H)$ of the Ni-Cr alloy electrodeposited to the frequency $(f)$, duty cycle $(D)$, current density $(i)$ and temperature $(T)$.

$$
\begin{gathered}
H=+674.51-59.80 f+0.62 i+27.48 D-16.51 T+ \\
57.20 f i-2.10 f D+38.38 f T-53.85 i D- \\
15.58 i T-11.52 D T-22.43 f^{2}-63.33 i^{2}- \\
31.81 D^{2}+16.67 T^{2}
\end{gathered}
$$

This equation can be used to predict the hardness of the Ni-Cr alloy electrodeposits in pulse electrodeposition. It can be seen from contour plots (Fig. 1) and the factor coefficients in Eq. (1), the parameters, $f$ (frequency) and $i^{2}$ (current density) are more effective than other parameters. Alongside the linear behavior of four substantial factors, the CCD found the quadratic and interaction effects of the parameters on each other. Quadratic effect of current density is noticeable in Eq. (1). Adequacy of the selected model is important and it can be identified by ANOVA. Fisher's test ( $F$ test) was used to recognize an appropriate model for prediction of the hardness. Generally, a model with an appropriate ' $F$ ' value and low ' $P$ ' value is acceptable model ${ }^{[24]}$. Table 3 illustrates the ANOVA table which it acknowledges that the Eq. (1) is statistically significant. It is observable that the $\mathrm{F}$ values for quadratic and cubic models are less than two other models. Quadratic model is selected as an appropriate prediction model although the $F$ value of cubic model is less than quadratic model. Lower $P$ value of quadratic model is the reason of this selection.

For evaluating the normality of a data set, using normal probability plots (NPP) is useful. The residuals are normally distributed if the residuals fall approximately along a straight line. Here residual means difference in the observed value and the predicted value ${ }^{[25]}$. Fig. 2 illustrates the normal probability plot of residuals in this study. It can be seen that the residuals are normally distributed.

The next objective of this study was optimization of the frequency, duty cycle, current density and bath 
Table 2 Experimental design for electrodeposition of the Ni-Cr alloy by pulse current

\begin{tabular}{|c|c|c|c|c|c|}
\hline Standard order & Run & Frequency $(\mathrm{Hz})$ & Current density $\left(\mathrm{A} / \mathrm{dm}^{2}\right)$ & Duty cycle (\%) & Temperature $\left({ }^{\circ} \mathrm{C}\right)$ \\
\hline 1 & 7 & 63.25 & 16.25 & 45 & 31.25 \\
\hline 2 & 19 & 187.75 & 16.25 & 45 & 31.25 \\
\hline 3 & 25 & 63.25 & 28.75 & 45 & 31.25 \\
\hline 4 & 6 & 187.75 & 28.75 & 45 & 31.25 \\
\hline 5 & 30 & 63.25 & 16.25 & 75 & 31.25 \\
\hline 6 & 8 & 187.75 & 16.25 & 75 & 31.25 \\
\hline 7 & 9 & 63.25 & 28.75 & 75 & 31.25 \\
\hline 8 & 17 & 187.75 & 28.75 & 75 & 31.25 \\
\hline 9 & 27 & 63.25 & 16.25 & 45 & 43.75 \\
\hline 10 & 4 & 187.75 & 16.25 & 45 & 43.75 \\
\hline 11 & 14 & 63.25 & 28.75 & 45 & 43.75 \\
\hline 12 & 20 & 187.75 & 28.75 & 45 & 43.75 \\
\hline 13 & 15 & 63.25 & 16.25 & 75 & 43.75 \\
\hline 14 & 3 & 187.75 & 16.25 & 75 & 43.75 \\
\hline 15 & 5 & 63.25 & 28.75 & 75 & 43.75 \\
\hline 16 & 16 & 187.75 & 28.75 & 75 & 43.75 \\
\hline 17 & 11 & 1 & 22.5 & 60 & 37.5 \\
\hline 18 & 13 & 250 & 22.5 & 60 & 37.5 \\
\hline 19 & 26 & 125.5 & 10 & 60 & 37.5 \\
\hline 20 & 2 & 125.5 & 35 & 60 & 37.5 \\
\hline 21 & 24 & 125.5 & 22.5 & 30 & 37.5 \\
\hline 22 & 22 & 125.5 & 22.5 & 90 & 37.5 \\
\hline 23 & 28 & 125.5 & 22.5 & 60 & 25 \\
\hline 24 & 12 & 125.5 & 22.5 & 60 & 50 \\
\hline 25 & 18 & 125.5 & 22.5 & 60 & 37.5 \\
\hline 26 & 29 & 125.5 & 22.5 & 60 & 37.5 \\
\hline 27 & 21 & 125.5 & 22.5 & 60 & 37.5 \\
\hline 28 & 10 & 125.5 & 22.5 & 60 & 37.5 \\
\hline 29 & 23 & 125.5 & 22.5 & 60 & 37.5 \\
\hline 30 & 1 & 125.5 & 22.5 & 60 & 37.5 \\
\hline
\end{tabular}

Table 3 ANOVA of the models which can predict the hardness of the Ni-Cr alloy electrodeposits

\begin{tabular}{cccccc}
\hline Source & Sum of squares & DF & Mean square & $F$ Value & $P$ Value \\
\hline Linear & $4.426 \times 10^{5}$ & 20 & 22131.21 & 3.75 & 0.0740 \\
2FI & $3.142 \times 10^{5}$ & 14 & 22444.68 & 3.80 & 0.0741 \\
Quadratic & $1.611 \times 10^{5}$ & 10 & 16107.74 & 2.73 & 0.1396 \\
Cubic & 13952.85 & 2 & 6976.42 & 1.18 & 0.3798 \\
Pure error & 29506.37 & 5 & 5901.27 & & \\
\hline
\end{tabular}
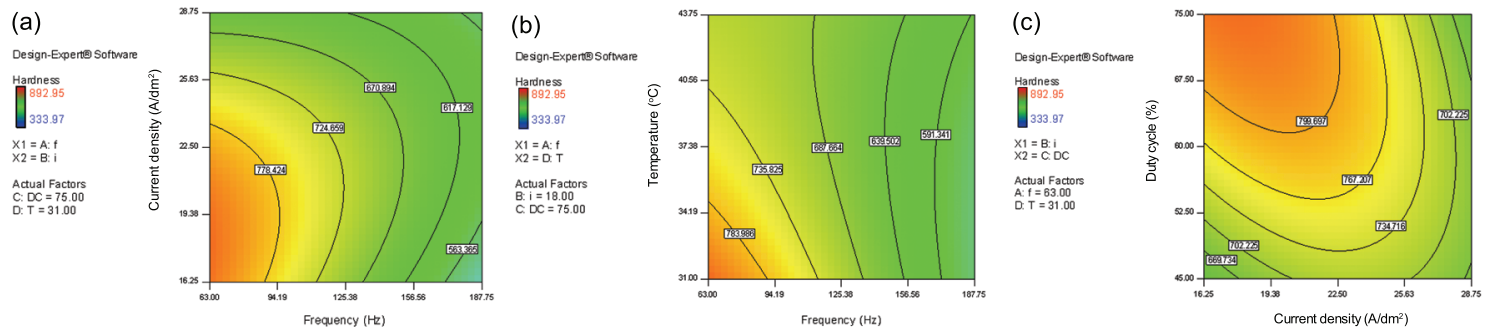

Fig. 1 Contour plots showing the effects of various parameters on the hardness of the Ni-Cr alloy electrodeposits: (a) frequency and current density; (b) frequency and temperature; (c) current density and duty cycle

temperature for obtaining the best hardness for the Ni-Cr alloy electrodeposits. The effects of these significant factors on hardness were depicted by surface and contour plots. In these plots two fac- tors varies while two other factors keep constant. Fig. 1 illustrates the contour plots of this study. In this figure, the results with the same hardness are connected to each other to produce contour 


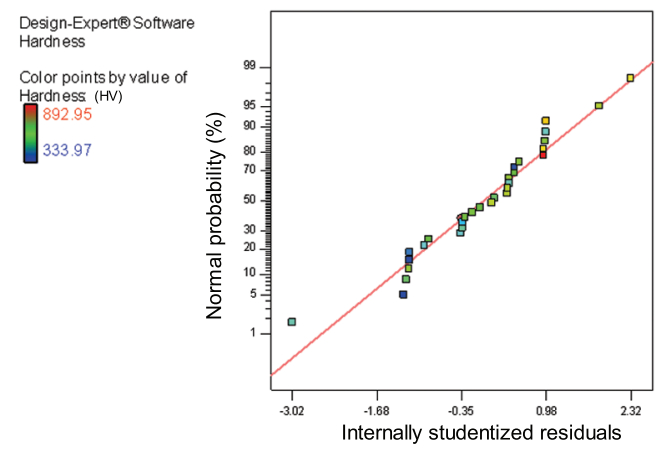

Fig. 2 Normal Probability Plot of residuals for the hardness (vickers micro-hardness) of the $\mathrm{Ni}-\mathrm{Cr}$ alloy electrodeposits

lines of a constant hardness. In this case the response surface is viewed in a two dimensional plane. Generally, circular contour lines are the evidence of no interaction between two considered factors. In contrary, elliptical contour lines are the evidence of serious interaction between two considered factors ${ }^{[26]}$. Contour plots indicate serious interactions between all factors except frequency and duty cycle. In Fig. 1(a) maximum of the hardness is obtained when the frequency and current density are in low levels and minimum hardness is obtained when the frequency is in high levels and the current density is in low levels. Other regions in this contour plot exhibit the medium condition of hardness. At the beginning of each pulse the cathode potential must be raised up to a specific value, to deposit metal on the cathode surface due to capacitor rule of electrical double layer in front of the cathode interface. If the charge and discharge times of the double layer become more than the on and off periods in pulses, damping will happen and cause unsuccessful deposition ${ }^{[27]}$. So the frequency value can play a significant role in pulse systems. Results in $\mathrm{Ni}-\mathrm{Cr}$ alloy electrodeposition show that frequencies more than $100 \mathrm{~Hz}$ do not have appropriate responses (Fig. 1(a)).

By varying plating current density from 10 to $40 \mathrm{~A} / \mathrm{dm}^{2}$, Ni-Cr alloy deposits with different $\mathrm{Cr}$ and $\mathrm{Ni}$ contents can be obtained in a trivalent chromium and divalent nickel ions solution ${ }^{[28]}$. It is found that the Ni content will decrease by increasing the current density. Studies have pointed out that the $\mathrm{Cr}$ rich alloys have many cracks in their structures because of high residual stresses in the $\mathrm{Cr}$ deposits and the creation of hydrogen bubbles during electrodeposition $^{[28]}$. So finding an optimum value for current density to achieve the best hardness can be useful. Fig. 1(a) illustrates that the current density range $16-22 \mathrm{~A} / \mathrm{dm}^{2}$ is appropriate.

Fig. 1(b) exhibits that the best hardness is obtainable in low frequencies and temperatures. On the other hand, increasing the bath temperature will reduce the amount of hardness. Our studies in the effects of temperature and frequency on the chromium

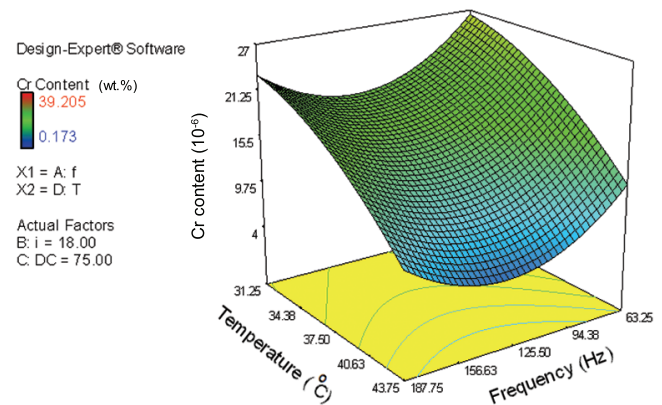

Fig. 3 Quadratic Surface plots showing the effects of frequency and temperature on the $\mathrm{Cr}$ content of the $\mathrm{Ni}-\mathrm{Cr}$ alloy electrodeposits

content can explain this behavior (Fig. 3). Declining effect of the temperature on the $\mathrm{Cr}$ content is absolutely visible in this Figure. Also maximum value of the $\mathrm{Cr}$ content is obtained in the low levels of the frequency. Previously the relation between the Cr content and the hardness is found and reported by Huang et al. ${ }^{[29]}$. They indicated that, the hardness of the Ni$\mathrm{Cr}$ alloy will be improved by increasing the $\mathrm{Cr}$ content. Therefore it is worthwhile to use low frequency and bath temperature in order to obtain better hardness. Moreover they indicated that $\mathrm{Cr}$ adding to the $\mathrm{Ni}$ structure will develop the crack networks in the structures. SEM images (Fig. 4) indicate the effect of the frequency on the microstructure of $\mathrm{Ni}-\mathrm{Cr}$ alloy. It can be seen that, the increase in the frequency leads to elimination of the cracks between the colonies and the continuous increase in intensify amount of frequency, the cracks will appear again. Frequency effect on the $\mathrm{Cr}$ content (Fig. 3) can explain this phenomenon. It can be seen that the increase in the frequency from 63 to $130 \mathrm{~Hz}$, the $\mathrm{Cr}$ content is diminished and continuing increase the frequency up to $200 \mathrm{~Hz}$, the $\mathrm{Cr}$ content increases again. Therefore appearance and disappearance of the cracks network in the microstructures shown in Fig. 4 can be related to the $\mathrm{Cr}$ content variation. So it is worth to mention that all factors effecting on the $\mathrm{Cr}$ content should be optimized for having a hard alloy with low cracks.

Duty cycle effect versus current density is shown in Fig. 1(c). Duty cycles more than $60 \%$ and current densities lower than $22 \mathrm{~A} / \mathrm{dm}^{2}$ are acceptable values for two factors. Elliptical contour lines indicate serious interaction of the current density and the duty cycle. On the other hand, $75 \%$ duty cycle is not appropriate value in all current density values and it is just acceptable for current densities lower than $20 \mathrm{~A} / \mathrm{dm}^{2}$. Again, this phenomenon can be related to the amount of the $\mathrm{Cr}$ content. Average current density can adjust the amount of chromium ${ }^{[27]}$. As mentioned previously, optimum value of $\mathrm{Cr}$ content can improve the hardness of the deposits.

The most important step in optimization research is to predict the response at the optimal settings. Then confirmation run to verify prediction point is 
Table 4 The prediction point and $95 \%$ confidence and prediction intervals ranges for pulse electrodeposition of the $\mathrm{Ni}-\mathrm{Cr}$ alloy

\begin{tabular}{ccccc}
\hline Factor & Name & Level & Low level & High level \\
\hline $\mathrm{A}$ & $\mathrm{f}(\mathrm{Hz})$ & 63.25 & 63.25 & 187.75 \\
$\mathrm{~B}$ & $i\left(\mathrm{~A} / \mathrm{dm}^{2}\right)$ & 17.99 & 16.25 & 28.75 \\
$\mathrm{C}$ & $D(\%)$ & 75.00 & 45.00 & 75.00 \\
$\mathrm{D}$ & $T\left({ }^{\circ} \mathrm{C}\right)$ & 31.25 & 31.25 & 43.75 \\
Hardness & 828.182 & 663.15 & 993.21 & $536.71-1119.66$ \\
& (Prediction) & $(95 \%$ CI low) & $(95 \%$ CI high) & $(95 \%$ PI low and 95\% PI high) \\
\hline
\end{tabular}
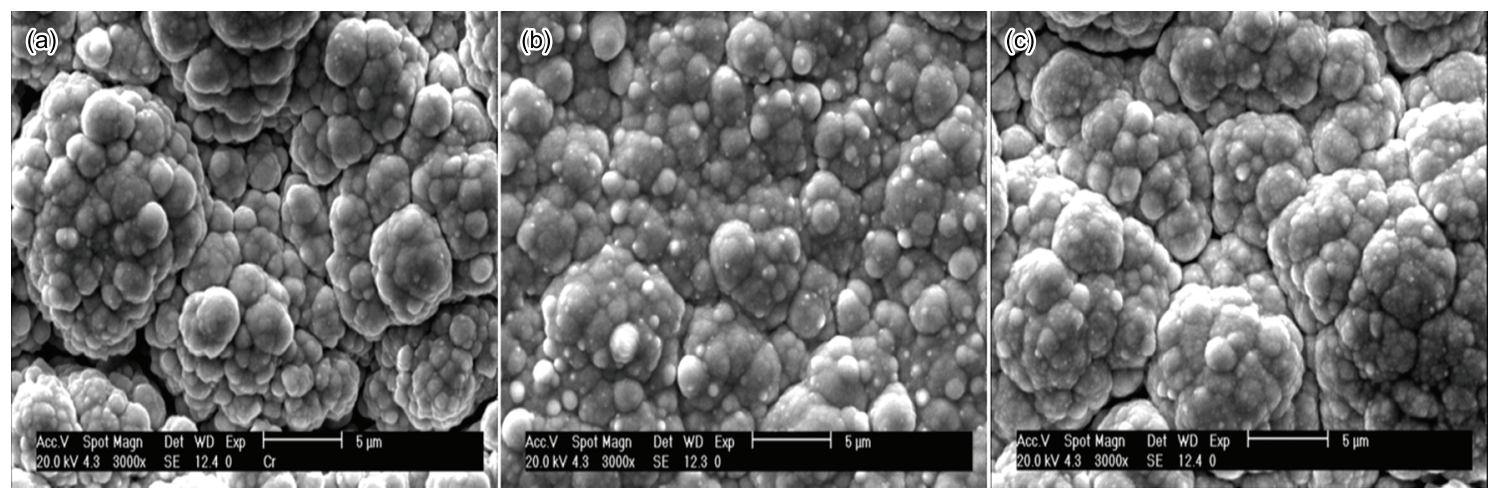

Fig. 4 SEM images of the Ni-Cr alloy electrodeposits: (a) standard order 17 with frequency $1 \mathrm{~Hz}$; (b) standard order 25 with frequency $126 \mathrm{~Hz}$; (c) standard order 18 with frequency $250 \mathrm{~Hz}$ (standard orders based on Table 2)
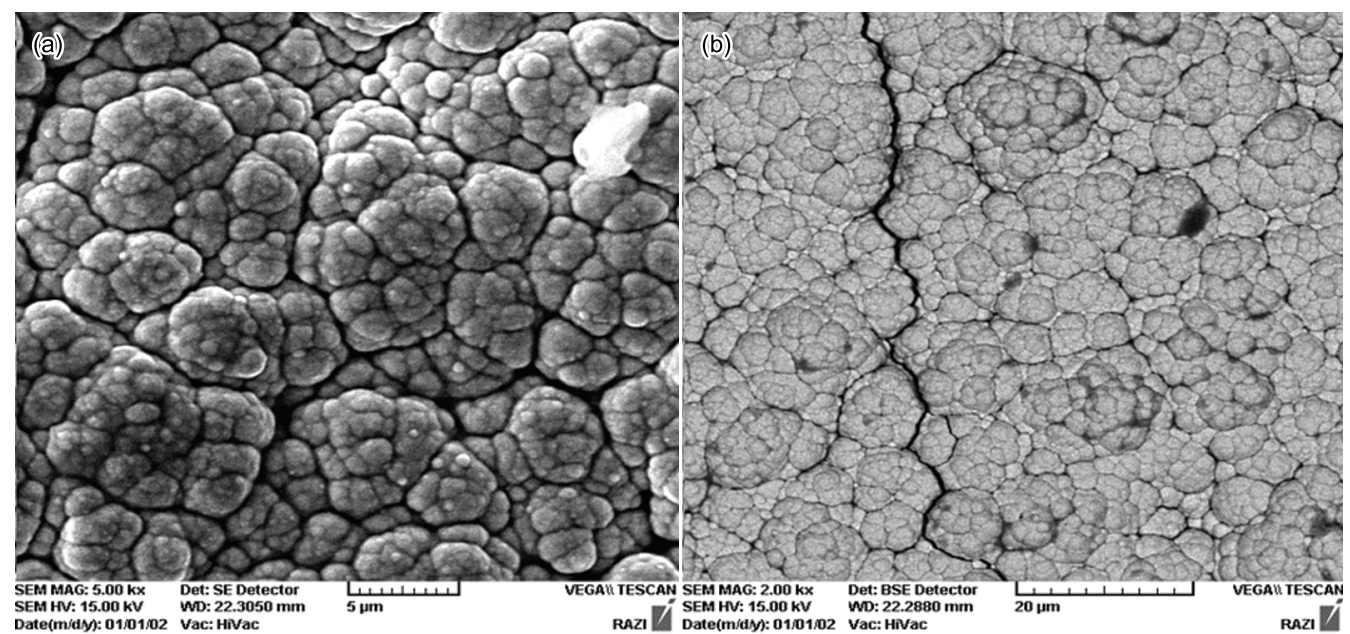

Fig. 5 SEM images of optimized Ni-Cr alloy electrodeposits: (a) secondary electron image; (b) back scatter image

essential. Point prediction allows us to enter levels for each factor or component into the given model. Then, the expected responses and associated confidence intervals will be calculated based on the prediction equation ${ }^{[30]}$. Table 4 illustrates the prediction point and $95 \%$ confidence and prediction intervals range for hardness optimization of the $\mathrm{Ni}-\mathrm{Cr}$ alloy electrodeposition. It is evident that these four selected levels for the frequency, current density, duty cycle and temperature will give a deposit with the hardness of $828 \mathrm{HV}$. The confidence interval range of this prediction is (663-993) HV.

The morphology of the optimum sample is indicated in Fig. 5. The propagation of the cracks through the colonies of the $\mathrm{Ni}-\mathrm{Cr}$ spheres are detectable in back scatter image (Fig. 5(b)). These cracks will be increaseed by absorption of more chromium ions from the solution and we should try to keep them as minimum by using various strategies. Using optimization methodologies or finding an appropriate temperature and time of annealing can be usefull in this aim ${ }^{[9]}$.

Hardness evaluation was performed on the optimized coating. The mean hardness of the optimum sample was found to be about $815 \mathrm{HV}$ while the hardness $828 \mathrm{HV}$ was the predicted value of the software. It can be observed that, there is no substantial difference between the real and predicted values of the hardness. Fig. 6 illustrates the predicted values of the 
Table 5 Corrosion behavior of optimized deposit of the Ni-Cr alloy electrodeposition and Ni-rich electrodeposition with condition of the $10^{\text {th }}$ experiment in designed experiments (Table 2)

\begin{tabular}{clccccc}
\hline Deposit & $E_{\text {corr }}(\mathrm{V})$ & $I_{\text {corr }}(\mu \mathrm{A})$ & Polarization resistance $(\Omega)$ & Corrosion rate $(\mathrm{mm} / \mathrm{y})$ & $\beta_{\mathrm{a}}$ & $\beta_{\mathrm{c}}$ \\
\hline Optimized deposit & -0.637 & 0.254 & 2469 & 0.002952 & 0.003 & 0.002 \\
Ni-rich deposit & -0.667 & 0.906 & 1028 & 0.010532 & 0.004 & 0.003 \\
\hline
\end{tabular}

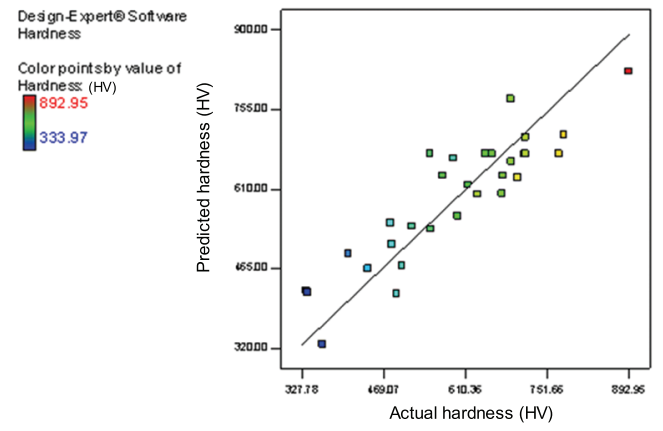

Fig. 6 Predicted hardness vs. actual hardness plot of NiCr alloy electrodeposits by pulse plating

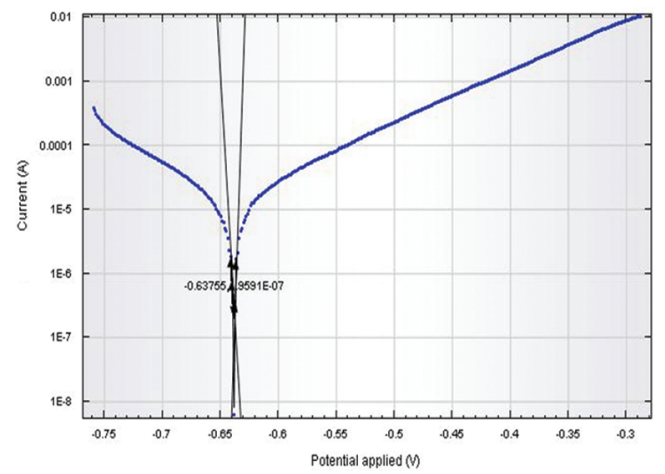

Fig. 7 Polarization curve of the Ni-Cr alloy electrodeposits at optimized condition with demonstration of Tafel slops

hardness versus actual values. It is evident that, except some points are far from the standard line, other points are near to the standard line. It means that probability of correct prediction in this case is acceptable. The hardness of the each point is depicted by colors.

Corrosion behavior of the optimum sample is studied in 3.5 wt.\% $\mathrm{NaCl}$ solution. Cathodic and anodic branches are plotted and corrosion rate is extracted by linear polarization method. A polarization resistance measurement is also done at a span of $50 \mathrm{mV}$ around the corrosion potential. The corrosion potential is $-0.64 \mathrm{~V}$ vs. $\mathrm{Ag} / \mathrm{AgCl}$ standard electrode. Polarization resistance measurement around this potential is $2469.1 \Omega$, corresponding to 0.003 $\mathrm{mm} / \mathrm{y}$ corrosion rate. Corrosion current density is found to be $0.254 \mu \mathrm{A} / \mathrm{cm}^{2}$. Fig. 7 illustrates the polarization curve of the optimum coating. Corrosion studies are also done (Fig. 8) on the $\mathrm{Ni}$ rich electrodeposits to evaluate the effect of $\mathrm{Cr}$ alloying. The corrosion results are summarized in Table 5 where the corrosion resistance is increased in the optimum coating. So besides the hardness

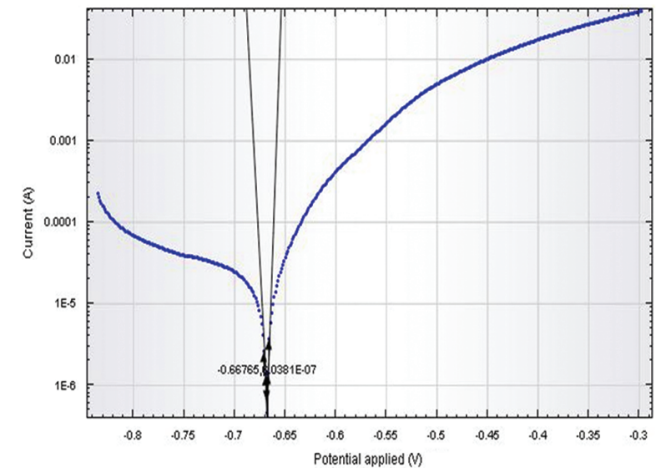

Fig. 8 Polarization curve of the Ni-rich alloy electrodeposits $\left(10^{\text {th }}\right.$ experiment in designed experiments) with demonstration of Tafel slops

improvement of the Ni-Cr alloy electrodeposit, its corrosion resistance is improved by $\mathrm{Cr}$ alloying. By using EDX analysis, the optimum deposit of $\mathrm{Ni}, \mathrm{Cr}$ and $\mathrm{Fe}$ is 64.78 wt. $\%, 34.59$ wt. $\%$ and 0.63 wt.\%. Iron detection is related to substrate supposedly.

\section{Conclusions}

Frequency, current density, duty cycle and temperature are the most important factors in hardness optimization of the Ni-Cr alloy electrodeposits. Frequency can affect the hardness of the deposits by its effect on the $\mathrm{Cr}$ content and the time of charging and discharging of the double layer. In summary, frequencies less than $100 \mathrm{~Hz}$ are more recommended for hardness improvement purposes in the $\mathrm{Ni}-\mathrm{Cr}$ alloy coatings. Other factors also have serious effect on the $\mathrm{Cr}$ content and their effects can influence the hardness of the deposits. Average current density which is derived from the amount of current density and duty cycle showed serious effects on the $\mathrm{Cr}$ content and particulary on the hardness. Generally electrodeposition with high current density will absorb more $\mathrm{Cr}$ ions on the cathode surface and it is a positive point for hardness improvment. But chromium absorption has a negative effect also due to crack propagation through the microstructure. Therefore finding an optimum value of it is essential. Declining effect of the temperature on the $\mathrm{Cr}$ content and hardness is also found in this study. Optimizing all factors by considering their interactions on each other is performed and reported in this study and the result is frequency $63 \mathrm{~Hz}$, current density $18 \mathrm{~A} / \mathrm{dm}^{2}$, duty cycle $75 \%$ and temperature $31^{\circ} \mathrm{C}$.

\section{REFERENCES}

[1] R. Mishra and R. Balasubramaniam, Corros. Sci. 46 
(2004) 3019.

[2] L.Y. Qin, J.S. Lian and Q. Jiang, Trans. Nonferrous Met. Soc. China 20 (2010) 82.

[3] A.M. Rashidi, Surf. Coat. Technol. 205 (2011) 4117.

[4] E. Mccafferty, Corros. Sci 44 (2002) 1393.

[5] A. Galtayries, A. Machet, P. Jolivet, P. Scott, M. Foucaut, P. Combrade, P. Marcus, M. Philippe and M. Vincent, in Passivation of Metals and Semiconductors, and Properties of Thin Oxide Layers, Elsevier Science, Amsterdam, 2006, pp. 403-409.

[6] P. Gencheva and T. Tzvetkoff, Mater. Chem. Phys. 92 (2005) 505.

[7] M.S. Chandrasekar and M. Pushpavanam, Electrochim. Acta 53 (2008) 3313.

[8] L. Hallez, M.D. Petris-Wery, M. Assoul, M. Feki and H.F. Ayedi, J. Appl. Electrochem. 37 (2007) 843.

[9] C.A. Huang, C.K. Lin and C.Y. Chen, Surf. Coat. Technol. 203 (2009) 3320.

[10] Y.F. Yang, Z. Gong, L. Deng, B. Luo, Y. Ma and Z. Yang, E. Vasheghani-Farahani, A. HeidarzadehVazifekhoran, A. Shojaosadati, P. Karmzadeh, K.kh. Darani, Sought Univ. Technol. 13 (2006) 1005.

[11] P. Lima-Neto, A.N. Correia and G.P. Da Silva, Chem. Soc. 17 (2006) 1419.

[12] H.C. Cheng, K.Y. Hsieh and K.M. Chen, Microelectron. Reliability 51 (2011) 826.

[13] H.L. Man, S.K. Behera and H.S. Park, J. Environ. Sci. Technol. 7 (2010) 157.

[14] A. Tosun and M.B. Ergun, J. Chem. Technol. Biotechnol. 82 (2007) 11.

[15] Z. Mokhtari-Hosseini, E. Vasheghani-Farahani, A. Heidarzadeh-Vazifekhoran, A. Shojaosadati, R. Karimzadeh and K.Kh. Darani, Bioresource Technol. 100 (2009) 2436.
[16] M.S. Bhatti, A.S. Reddy, R.K. Kalia and A.K. Thukral, Desalination 269 (2011) 157.

[17] B. Wahdame, D. Candusso, X. Francois, F. Harel, J. Kauffmann and G. Coquery, Int. J. Hydrogen Energy 34 (2009) 967.

[18] K. Ravikumar, K. Pakshirajan, T. Swaminathan and K. Balu, J. Chem. Eng. 105 (2005) 131

[19] M.S. Jo, E.R. Rene, S.H. Kim and H.S. Park, J. Hazard. Mater. 152 (2008) 1276.

[20] M. Poroch-Seritan, S. Gutt, Gh. Gutt, I. Cretescu, C. Cojocaru and T. Severin, Chem. Eng. Res. Design 89 (2011) 136.

[21] M.S. Bhatti, D. Kapoor, R.K. Kalia, A.S. Reddy and A.K. Thukral, Desalination 274 (2011) 74.

[22] X.T. Yuan, D. Sun, H. Yu, H. Meng, Z. Fan and X. Wang, Surf. Coat. Technol. 202 (2007) 294.

[23] D.C. Montgomery, Design and Analysis of Experiments, 4th ed., John Wiley and Sons, New York, 1997.

[24] E.R. Rene, M.S. Jo, S.H. Kim and H.S. Park, J. Environ. Sci. Technol. 4 (2007) 177.

[25] J. Antony, Design of Experiment for Engineers and Scientists, Elsevier Science \& Technology Books New York, 2003.

[26] R. Muralidhar, S.N.Gummadi, V.V.Dasu, T.Panda, J. Biochem. Eng 16 (2003) 229.

[27] F. Leaman, Theory and Practice of Pulse Plating, American Electroplaters and Surface Finishers Society, 1909.

[28] C.A. Huang, C.Y. Chen, C.C. Hsua and C.S. Lin, Scr. Mater. 57 (2007) 61.

[29] C.A. Huang and C.Y. Chen, Surf. Coat. Technol. 203 (2009) 3320.

[30] R.G. Brereton, Applied Chemometrics for Scientists, John Wiley \& Sons, Ltd, UK, 2007. 